\title{
A PRESENÇA DE UNIDADES FRASEOLÓGICAS NA LITERATURA POPULAR CEARENSE
}

\author{
THE PRESENCE OF PHRASEOLOGICAL UNITS IN \\ CEARENSES' POPULAR LITERATURE
}

Maria Silvana Militão de ALENCAR

Universidade Federal do Ceará

msmilitao@gmail.com

\footnotetext{
"Um povo que não ama as suas formas de expressão mais autênticas jamais será um povo livre”. (Plínio Marcos)
}

Resumo: A língua como produto social reflete a cultura e a sociedade em que se vive. Cultura vista como conhecimento adquirido socialmente, e sociedade definida como grupo de pessoas que têm objetivos e interesses comuns ou semelhantes. A língua é, ao mesmo tempo, a história de um povo. Pretende-se, com este trabalho, observar o uso de parêmias (provérbios) e expressões idiomáticas registradas na Literatura Popular Cearense, considerando a poesia de Patativa do Assaré e o romance Dona Guidinha do Poço, de Manuel de Oliveira Paiva. Justifica-se pela necessidade de preservar e valorizar os traços linguísticos e culturais cearenses que, embora relegados a um segundo plano, retratam a história e a cultura desse povo. Utiliza-se a Fraseologia como uma abordagem acadêmica da língua, juntamente com a Etnolinguística por se tratar de um estudo do léxico em relação à cultura.

Palavras-chave: Fraseologia; Paremiologia; Etnolinguística; Literatura Popular Cearense.

Abstract: Language as a social product reflects the culture and society in which it lives. Culture seen as socially acquired knowledge, and society defined as a group of people who have common or similar goals and interests. The language is, at the same time, the history of a people. It is intended, with this work, to observe the use of paremias (proverbs) and idioms registered in Cearense Popular Literature, considering the poetry of Patativa do Assaré and in the novel Dona Guidinha do Poço, written by Manuel de Oliveira Paiva. It is justified by the need to preserve and enhance the linguistic and cultural traits of Ceará, which, although relegated to a secondary level, portray the history and culture of this people. Phraseology is used as an academic approach to language together with Ethnolinguistics as it is a study of the lexicon in relation to culture.

Key-words: Phraseology; Paremiology; Ethnolinguistics; Popular Literature from Ceará. 


\section{CONSIDERAÇÕES PRELIMINARES}

O presente trabalho objetiva analisar o uso de parêmias (provérbios) e expressões idiomáticas registradas na literatura popular cearense, considerando a poesia de Patativa do Assaré e o romance de autoria do escritor cearense Manuel de Oliveira Paiva.

O Ceará, assim como os demais estados nordestinos, possui autores de literatura regional/popular de renome nacional, como: Patativa do Assaré, Manoel de Oliveira Paiva, Gustavo Barroso, Ildefonso Albano, Juvenal Galeno, Franklin Távora, Leonardo Mota, dentre outros, que retratam de modo fiel, não apenas a linguagem regional do Ceará, mas a cultura, o modo de ser, viver e pensar dos cearenses. Através da fala, apreende-se, não só a mensagem do autor, mas dados identificadores de seu universo sócio-linguístico-cultural, bem como de sua visão de mundo. Justifica-se, também, pela necessidade de preservar e valorizar os traços linguísticos e culturais cearenses que, embora relegados a um segundo plano, retratam a história e a cultura desse povo, afinal, a língua é a organização da realidade que nos cerca, refletindo uma visão de mundo e, revelando, ao mesmo tempo, valores, costumes e sentimentos. Mostra-se, também, a importância de que se revestem as pesquisas empíricas para o conhecimento da realidade linguística do português falado no Brasil.

A Fraseologia é utilizada como uma abordagem acadêmica da língua, juntamente com a Etnolinguística por se tratar de um estudo do léxico em relação à cultura. Nesse trabalho, analisa-se a indissociável relação existente entre a cultura e a expressividade da linguagem popular. São apresentados exemplos retirados de poesias escolhidas, de forma aleatória, dos livros Cante lá que eu canto cá e Aqui tem coisa, de Patativa do Assaré, e do romance Dona Guidinha do Poço, de Manuel de Oliveira Paiva.

\section{FRASEOLOGIA/PAREMIOLOGIA}

Segundo Barbosa (2006, p. 4), "a fraseologia é um dos ramos das ciências da palavra que tem por objeto de estudo as unidades lexicais constituídas de dois ou mais vocábulos ou de sintagmas e de frases, com grau variável de lexicalização".

Um dos principais problemas da Fraseologia é a classificação das unidades fraseológicas (UF) ou fraseologismos, seu objeto de estudo. Para Corpas Pastor (1996, p. 17), a Fraseologia constitui o "conjunto de frases hechas, locuciones figuradas, metáforas y comparaciones fijadas, modismos y refranes, existentes en una lengua, en el uso individual o en el de algún grupo".

As unidades fraseológicas (UF) refletem a vida livre das palavras. Essas construções nascem das mais diversas atividades culturais de que os falantes participam. Depois, tornam-se metáforas, metonímias lexicalizadas e gramaticalizadas. Delas, nasce a visão 
crítica do falante em relação às pessoas e à sociedade, de tal forma, que passa a fazer parte do conhecimento linguístico de uma comunidade.

Por serem bastante complexas, as UF são de difícil classificação. Corpas Pastor (1996) apresenta uma subdivisão dessas unidades em três grupos: colocações, locuções e enunciados fraseológicos, sendo esta última dividida em parêmias (provérbios) e fórmulas rotineiras. As colocações, bem como, as locuções são chamadas de expressões idiomáticas (EI) e fazem parte do sistema da língua, enquanto as parêmias, que chamamos provérbios, são unidades de fala. O anonimato é outra característica que diferencia os provérbios das demais UF, exceto o Livro dos Profetas, no Novo Testamento, cuja autoria é atribuída ao Rei Salomão.

De acordo com Ortiz Alvarez (2004), a Fraseologia pode ser entendida como uma combinação de elementos linguísticos de uma determinada língua, relacionados semântica e sintaticamente, que não pertencem a uma categoria gramatical específica e cujo significado é dado pelo conjunto de seus elementos. Quem já embarcou em uma canoa furada, passou por uma vereda ou viu um olho de boi em um dia de chuva? Quer dizer, fez um péssimo negócio, passou por um caminho estreito e viu um arco-íris em dia de chuva. Muitos brasileiros desconhecem os significados dessas expressões.

Na fraseologia, estão inseridos: brasileirismos, ditados populares, máximas, provérbios, frases feitas e de efeito, outras formas do falar informal, tudo enfim, que compõe o universo das unidades fraseológicas. Conforme Lapa (1998, p. 66), “todos os elementos do grupo concorrem para nos darem uma idéia (sic) única: as partes componentes sacrificam o seu significado individual em benefício do conjunto". Daí o interesse particular, sempre crescente, não só para o falante nativo, como para o estrangeiro, pelos estudos fraseológicos ao desejar compreender a língua do outro e realizar uma comunicação plena.

No âmbito da Fraseologia, situa-se a Paremiologia (do grego paroimía, provérbio + logos, tratado), como a ciência que estuda as unidades paremiológicas (UP), ditados, provérbios, anexins e outras construções tradicionais, baseadas na experiência de uma comunidade em situação de uso e transmitidas de geração a geração.

Combet (apud CORPAS PASTOR, 1996, p. 150) conceitua provérbio como "uma frase independente, anônima e popular que, em forma elíptica, direta ou preferencialmente figurada, expressa poeticamente, um ensinamento, um conselho moral ou um conselho prático".

Através da Fraseologia/Paremiologia pode-se fazer uma correlação ao emprego de unidades fraseológicas/paremiológicas cristalizadas, no estudo que nos interessa. O que, tradicionalmente, era visto, apenas, como expressão popular, no dizer de Ortiz Alvarez (2000) assume as seguintes características: i) as expressões idiomáticas são caracterizadas, sobretudo, por sua motivação metafórica que pode ser explícita ou implícita; ii) referem- 
se a situações específicas, sendo parte integrante do discurso; e iii) podem exercer várias funções dentro de um texto, por exemplo, exteriorizar, satirizar a complexidade de uma argumentação ou valores ideológicos, permitindo ao falante ironizar ou sugerir sutilmente o que não se ousa pedir ou criticar diretamente.

\section{RELAÇÕES ENTRE LÉXICO E CULTURA}

Toda língua possui um fundo lexical que é constituído por um conjunto de palavras guardadas na memória de uma comunidade de fala, durante sua existência e, como tal, expressa a história dessa comunidade e a estrutura organizacional das normas sociais que a regem. Dessa forma, as mudanças no vocabulário estão relacionadas, de algum modo, com as mudanças sociais. Nesse sentido, Martinet (1974, p. 36) afirma que "é, com efeito, o léxico que, numa língua, reflete mais diretamente as realidades não linguísticas”.

O estudo do léxico é bastante complexo. É a parte da língua mais sensível às transformações. Através dele, melhor do que em qualquer outro nível de análise, podese observar a diversidade de visões de mundo, a dinamicidade da língua, sua incessante renovação para atender às necessidades de seus usuários e, ao mesmo tempo, como este universo lexical é constituído regionalmente.

O acervo lexical, da mesma forma que os costumes, submete-se a pressões sociais, consequentemente, formas populares caem de uso, enquanto outras se incorporam à norma culta. Como as palavras refletem o aspecto social, dentre elas, há as formas que gozam de maior prestígio social e as que são estigmatizadas, usadas, geralmente, pelos falantes rurais ou pouco escolarizados. Há, ainda, as que se ligam à tradição clássica e as mais recentes que surgem em virtude do desenvolvimento científico e tecnológico.

Silva Neto (1963, p. 210) aponta o contato como fator responsável pela mudança cultural. O isolamento, ao contrário "[...] condiciona um tipo arcaico de vida e, conseguintemente, uma linguagem mais conservadora”. É o que se observa na população rural. Como não há, nestas comunidades interioranas, o dinamismo e intercâmbio dos centros cultos, os falantes nativos são conservadores por excelência.

Nestes locais, uma expressão pode ser uma aula de história. Muito do que é desprezado pela elite culta como a forma incorreta de se exprimir, tem ligações com o português medieval. Expressões populares faladas no interior do Brasil, especialmente, no Nordeste, foram usadas por clássicos da língua cearense. Biderman (1992) afirmara que o léxico é a somatória de toda a experiência acumulada de uma sociedade e do acervo cultural, é um universo léxico-semântico aberto, em constante trabalho de renovação e ampliação. 
Além da função básica que é comunicar, a língua costuma ser interpretada, também, como produto da cultura da qual faz parte. A relação entre língua, cultura e sociedade funciona como determinante do objeto material de estudo da Linguística - a descrição das línguas. Trata-se de uma relação mais profunda do que se possa imaginar. A língua como sistema acompanha de perto a evolução da sociedade e reflete padrões de comportamento, que variam em função do tempo e do espaço.

A língua é adquirida por um processo de transmissão cultural. Esta definição está ligada ao fato de que os grupos têm línguas diferentes porque têm visões de mundo diferentes. A língua como produto social reflete a cultura e a sociedade em que se vive. Cultura vista como "conhecimento socialmente adquirido". E sociedade, definida como grupo de pessoas que têm objetivos e interesses comuns ou semelhantes.

Se a cultura muda, a língua, também, apresentará modificações que poderão ser movidas por fatores históricos, econômicos, sociais, dentre outros. As experiências linguísticas em um país gigantesco como o Brasil não podem coincidir de uma região para outra, justamente por causa destes fatores. Com efeito, a natureza e a vida das diversas regiões brasileiras trazem algumas alterações, modificações e acréscimos à língua.

A Etnolinguística, segundo Cosériu (1987, p. 28), "é o estudo da linguagem em relação com a civilização e a cultura das comunidades falantes". O objeto de estudo da Etnolinguística seria o estudo das estruturas socioculturais refletidas nas línguas, ou seja, estudar a mensagem linguística em relação com o conjunto de circunstâncias da comunicação.

É muito importante para o presente estudo saber o que se entende por cultura. Trata-se de um conceito utilizado nos mais diversos contextos e costuma ter diferentes definições. Um conceito clássico de cultura, por exemplo, refere-se ao grau de sabedoria que um indivíduo adquiriu através do seu trabalho intelectual. Pode-se observar, também, o conceito estético de cultura, que inclui objetos estéticos e artísticos. E, por fim, o conceito antropológico de cultura, representando padrões gerais de pensamento e ação do ser humano em tempo e espaço, o ethos cultural.

Há nessa interação, homem/natureza a necessidade de novas expressões, de novas formas de dizer as realidades regionais e sociais. Com essa nova forma de dizer, a língua ganha muitas palavras e expressões que conduzem, na maior parte das vezes, a diferenciações regionais e sociais bem nítidas. 


\section{UNIDADES FRASEOLÓGICAS NA \\ LITERATURA POPULAR CEARENSE}

A amostragem que em seguida será apresentada, extraída da sabedoria popular dos dois autores cearenses citados, ilustra a descontração de construções fraseológicas. Vilela (2002, p. 199) assevera que "as fraseologias são uma marca da linguagem da proximidade, da oralidade, da expressividade, da desconstrução, da horizontalidade discursivo-pragmática”. Cada nova unidade linguística constitui, com efeito, uma resposta às necessidades que surgem em uma nova situação social.

A seguir, abordam-se exemplos nas obras dos autores em estudo, Manoel de Oliveira Paiva (OP) e Patativa do Assaré (PA), ressaltando-se o papel social e cultural dessas unidades linguísticas, reflexos da linguagem popular. Para a análise dos dados, realizou-se pesquisa prévia em dois dicionários específicos, Dicionário de Termos e Expressões Populares, Cabral (1982), Tesouro da Fraseologia Brasileirano, Nascentes (1986) e no Vocabulário Popular Cearense, Girão (2000). Dessa forma, procurou-se analisar as UF documentadas do ponto de vista semântico-lexical e a questão da dicionarização das designações.

A entrada das UF é feita em itálico e contextualizada. Logo após, vem a definição do sentido usado pelo autor, confirmada e enriquecida a partir dos dicionários consultados, identificados através da sigla constituída por três letras, ou seja, Cabral (CAB), Nascentes (NAS) e Girão (GIR). Os termos não dicionarizados vêm antecedidos de asterisco.

\section{MANOEL DE OLIVEIRA PAIVA}

Manoel de Oliveira Paiva, jornalista e escritor cearense, entrou para a literatura brasileira com a publicação de Dona Guidinha do Poço, uma das melhores realizações do regionalismo. A obra foi escrita em 1879, mas publicada em 1952, quase sessenta anos depois, fora de seu contexto histórico e estético, a partir da descoberta dos seus originais pela autora de História da Literatura Brasileira, Lúcia Miguel Pereira.

O romance, Dona Guidinha do Poço, narra a história de um crime passional. Sua heroína, Dona Guida, senhora rica e orgulhosa, enfrenta os preconceitos da época, quebrando tradições e expondo-se aos riscos do adultério com um sobrinho do marido. A seguir, alguns exemplos de UF, de cunho regional/popular, utilizadas na obra do referido autor:

- De se tirar o chapéu - De causar admiração. _ Pois tenho uma tia de se lhe tirar o chapéu, meu amigo. (OP, 1999, p. 27; NAS, 1986, p. 66). De tirar o chapéu (CAB, 1982, p. 211). 
- Dá uns ares - Ar de família - Semelhança entre pessoas da mesma família. _ Gentes! Será parente de Seu Major? A mó de que inté nas feição dá uns ares!(OP, 1999, p. 26; NAS, 1986, p. 12). Dar uns ares (CAB, 1982, p. 54).

- Via com bons olhos - Receber bem, ter afeição, mostrar-se favorável. No seu temperamento e educação via com bons olhos a chegada de Secundino. (OP, 1999, p. 35; NAS, 1986, p. 206). Ver com bons olhos - Demonstrar interesse, acatamento. (CAB, 1982, p. 551).

- Comendo o pão que o diabo amassou - Sofrer privações, comer pouco e mal. ...comendo, e quando comiam! O pão que o diabo amassou. (OP, 1999, p. 32; NAS, 1986, p. 217). Comer o que o diabo ajuntou ou o pão que o diabo amassou - Sofrer dificuldades, trabalhos forçados, aperturas financeiras. $\mathrm{O}$ sinhô nunca sofreu/ Pois nunca comeu do pão/ Que o diabo tem amassado. (PA). (CAB, 1982, p. 239).

- Pé de pau - Árvore, tronco de árvore. ... lá de riba não cai uma folha de pé de pau.(OP, 1999, p. 32).... dizendo que foia de pé de pau, só pra sítio de Judas... (OP, 1999, p. 78). ... nunca se viu pé de pau dar tanta folha. (OP, 1999, p. 123; NAS, 1986, p. 226). Pé de pau ou pé de mato. (CAB, 1982, p. 507).

- Duro de roer - Coisa difícil de suportar, de vencer. Na verdade era duro de roer. (OP, 1999, p. 36; NAS, 1986, p. 208; CAB, 1982, p. 555).

- Matar o tempo - Gastar em ocupação que evita a inação, recrear-se, entreter-se. O rapaz nem se lembrava de abrir os livros de histórias e novelas que trazia, para matar o tempo. (OP, 1999, p. 40; NAS, 1986, p. 293).

- Lábias de labaral - Deixemo-nos de contos. Vamos direto ao fim, ponhamos de parte o subterfúgio, a mentira, o mexerico. _ Menino, lê lá, e deixa-te de lábias de labaral*. (OP, 1999, p. 49; NAS, 1986, p. 77).

- De fio a pavio - Do princípio ao fim, de ponta a ponta. _ Não interrompa, vá de fio a pavio. (NAS, 1986, p. 128; CAB, 1982, 393). De cabo a rabo. Do princípio ao fim. (NAS, 1986, p. 44).

- Tanto faz dar na cabeça como na cabeça dar - Tanto faz dar na cabeça como na cabeça dar... (OP, 1999, p. 49; NAS, 1986, p. 43). A ordem dos fatores não altera o produto. Tanto faz, como tanto fez. Pouco me interessa o caso. (CAB, 1982, p. 705).

- Dou cavaco - (dar importância, valor): Não dou cavaco in morrê,/ Somente por conhecê/ Que há tempo tá reservado/ O meu quadrinho de chão. (PA). Dar 
cavaco. Zangar-se, aborrecer-se. (GIR, 2000, p. 164). Dar o cavaco com. (NAS, 1986, p. 62). Dar cavaco ou Dar um cavaco. (CAB, 1982, p. 203).

- Pelo oco deste mundo - Fugir para lugar muito distante. Bateu pé pelo oco deste mundo, cá muié e os fio... (OP, 1999, p. 31; NAS, 1986, p. 202). Cair no oco do mundo. Ir embora, desaparecer. (CAB, 1982, p. 165). Ganhar o oco do mundo. (GIR, 2000, p. 277).

- Caisse nas graças - Ser alvo de simpatia. Feliz quem lhe caísse nas graças. (OP, 1999, p. 44; CAB, 1982, p. 164). Cair em graça de alguém. Merecer a simpatia, ser bem acolhido. (NAS, 1986, p. 142).

- Dar trela - Dar folga, licença, aceitar galanteios, dar confiança, puxar conversa. Dona Anginha a dar trela. (OP, 1999, p. 46). O Padre não gostou deste cavaco do fazendeiro. Ficara calado, deixando-o dar à trela. (Termo utilizado com o sentido de gozação - NE) (OP, 1999, p. 152; NAS, 1986, p. 303).

- Aos trancos e barrancos - À força, aos empurrões, ao léu da sorte. ... não se andava aos trancos e barrancos como ali na fazenda. (OP, 1999, p. 55; CAB, 1982, p. 98). Por trancos e barrancos. Com muitos trabalhos e riscos. (NAS, 1986, p. 302).

- Meteu-se no gole - Tomar um pileque. _ Você meteu-se no gole, Corumba. (NAS, 1986, p. 141). Meter-se na cana (na bebida, no porre). Beber muito, embriagar-se. (CAB, 1982, p. 517).

- Dava as cartas - Pôr e dispor. (NAS, 1986, p. 58). Ser senhor absoluto ou manda-chuva. ...ali onde ele estava quem dava as cartas eram os chimangos, (OP, 1999, p. 65; CAB, 1982, p. 196).

- Chita da mesma peça - Ser da mesma laia. São chita da mesma peça. Ser farinha do mesmo saco (OP, 1999, p. 69; CAB, 1982, p. 380). Ter o mesmo modo de vida, os mesmos hábitos. (NAS, 1986, p. 75).

- Cara de pau - Indivíduo antipático, insensível. Secundino estava demorando por denguice, que isso lá de cara de pau ele a tinha bastante. (OP, 1999, p. 70; CAB, 1982, p. 188). Cara-de-pau. Impassível, sem expressão. (NAS, 1986, p. 54). Cara dura. Cínico, insensível, desavergonhado. (GIR, 2000, p. 130).

- Na ponta da língua - Bem decorado. O Quim largou-se com a exposição na ponta da língua. (OP, 1999, p. 75; CAB, 1982, p. 475). Saber na ponta da língua. (NAS, 1986, p. 245). 
- Dá conta do recado - Desempenhar o encargo. ... aquele home non dá conta dos animais, (OP, 1999, p. 77). _ Cumade, disse, estou cage li dizendo qui discanse seu coração, que seu caba véio dá conta do recado... (OP, 1999, p. 156; NAS, 1986, p. 76). Ser exato na execução de um mister. (GIR, 2000, p. 164; CAB, 1982, p. 650).

- O mundo e as capas do fundo - Coisa difícil ou inverossímel. (CAB, 1982, p. 537). _ O Manjó hé de vê o mundo e as capas do fundo. (OP, 1999, p. 114). ... mais porém tenho visto mundo e as capa do fundo pra adquiri cum que me arremedeie... (OP, 1999, p. 144).

- Era tiro e queda - Ser coisa infalível, certa. Todos conheciam que a intercessão de Seá Dona Guida era tiro e queda. (OP, 1999, p. 83; CAB, 1982, p. 716). Decidir rapidamente um caso. (NAS, 1986, p. 298).

- Saiu do sério - Folgar, rir, perder por um pouco ar e caráter de gravidade. Só porque num fim de festa saiu do sério? (OP, 1999, p. 83; NAS, 1986, p. 282; CAB, 1982, p. 674).

- Corda no pescoço - Muito necessitado de dinheiro, muito endividado. Preços estravagantes, negocinho de beira de estrada, comércio de corda ao pescoço! (OP, 1999, p. 88; NAS, 1986, p. 80). Com a corda no pescoço. Em má situação financeira. (CAB, 1982, p. 249).

- Sem eira nem beira - Ser um pobretão. Às vezes se acrescenta: nem ramo de figueira. ... confiar a sorte de sua filha a um forasteiro, sem eira nem beira. (OP, 1999, p. 89; NAS, 1986, p. 107).

- Sem quê nem pra quê - Sem motivo plausível, sem razão justa. Chegava a ter dores de cabeça, assim a modo de defluxo, sem quê nem pra quê. (OP, 1999, p. 95; CAB, 1982, p. 634).

- Virasse casaca - Mudar de partido político. ... exceto algum que virasse casaca em favorável ocasião. (OP, 1999, p. 95; CAB, 1982, p. 197). Virar casaca. Por interesse mudar de opinião ou de partido. (NAS, 1986, p. 60).

- Faz esteira - (Ceará) $O$ ato de, na carreira, para derrubar a rês, um dos vaqueiros acompanhar de lado o outro que vai alcançá-la. São os dois o que vai cabear e o que faz esteira. (OP, 1999, p. 110; GIR, 2000, p. 199; NAS, 1986, p. 117; CAB, 1982, p. 368).

- Pondo os bofes pela boca - Ofegar de cansado, cansar-se de falar ou de trabalhar. Chegou em casa pondo os bofes pela boca, (OP, 1999, p. 119; NAS, 1986, p. 
33); Esbaforir-se (CAB, 1982, p. 121). Deitar os bofes pela boca. É mostrar-se extenuado. (GIR, 2000, p. 100).

- Voltando à vaca fria - Retomar o fio do que dizia, acabar com a digressão. Então, Vossa Mercê, Comadre Guidinha, que dá tudo por café... Mas voltando à vaca fria... (OP, 1999, p. 121; NAS, 1986, p. 309; CAB, 1982, p. 761).

- O fio da meada - Descobrir a maneira de esclarecer o que está confuso. Lá vai agora o fio da meada. (OP, 1999, p. 122; NAS, 1986, p. 128). Reatar o fio da conversa. Continuá-la do ponto onde havia parado. (NAS, 1986, p. 128).

- Non meto a mão no fogo por (alguém)- Não assegurar a inocência, a pureza desta pessoa. Eu non meto a mão no fogo por Pedo nem por Paulo. (OP, 1999, p. 137; NAS, 1986, p. 178). Botar a mão no fogo (Pôr ou Meter). Ter confiança cega em alguém. (CAB, 1982, p. 498).

- Ricos à vela de libra - Passar (Viver ou Ser tratado) à vela de libra. Viver, colher ou ser acolhido regiamente. Aquilo era tratado pelos homes ricos $\grave{a}$ vela de libra... (OP, 1999, p. 139; CAB, 1982, p. 747). Tratar à vela de libra. Excelentemente. Guida tratou-o como de costume, à vela de libra. (OP, 1999, p. 148; NAS, 1986, p. 311).

- Aparecer de sopetão (ou De Sopetão) - De súbito, abruptamente. ... fazer que está longe e aparecer de sopetão... (OP, 1999, p. 142; CAB, 1982, p. 696).

- Entrava-lhe por um ouvido, saía-lhe pelo outro - Não dar atenção, não fazer caso. Sabia lá! Entrava-lhe por um ouvido, saía-lhe pelo outro. Entrar por um ouvido e sair pelo outro. (OP, 1999, p. 142; NAS, 1986, p. 209). Não ligar, não importância. (CAB, 1982, p. 345).

- Com quatro pedras na mão - Com altivez, insolência. Havia-lhe falado franco. Ela porém, saíra-lhe com quatro pedras na mão... (OP, 1999, p. 152; NAS, 1986, p. 231). Com quatro pedras na mão. Estado da pessoa que se mostra grosseira, agressiva. (CAB, 1982, p. 499).

- Em cima das buchas - Imediatamente. Logo em seguida. ... nunca havia atacado ninguém a sangue-frio! Ferro e sangue, mas ali, em cima das buchas. (CAB, 1982, p. 140). Em riba das buchas (Ceará). (NAS, 1986, p. 39). Nas buchas ou Em cima das buchas. Imediatamente, sem demora. (GIR, 2000, p. 106).

- Mandara a mulher para a melhor - Matar. (NAS, 1986, p. 175). Ultimamente, mandara a mulher para a melhor... (OP, 1999, p. 155). Mandar desta para a melhor. Matar, assassinar. (CAB, 1982, p. 493). 
- Fica o dito por não dito - Desfazer um trato. (NAS, 1986, p. 88). ... mande entregá o cavalo em que eu vim, cos arreios, à Seá Dona Guida, e dizê a ela que fica o dito pelo não dito. (OP, 1999, p. 156).

- Tintim por tintim - Miudamente, minuciosamente, especificamente. (NAS, 1986, p. 297). Confessou tudinho, tintim por tintim. (OP, 1999, p. 160).

- Pôs-se no bredo - (Ceará). Fugir. Expressão utilizada com osentido de esconderse, escapar. O termo bredo é utilizado para designar o mato. (NAS, 1986, p. 38). O Silveira pôs-se no bredo, cabra desgraçado e traiçoeiro! (OP, 1999, p. 161). Cair no bredo. Pisar no bredo (ou Ganhar o bredo). Embrenhar-se no mato. (CAB, 1982, p. 136). Pisar no bredo. Ir embora; fugir desaparecer; meter-se no mato; sumir. Eu também corri com medo/ Não vou negar nem mentir,/ Tive que pisá no brêdo/ Tive que me escapuli. (PA).

\section{PATATIVA DO ASSARÉ}

Antônio Gonçalves da Silva, cognominado Patativa do Assaré, por analogia a uma ave canora, a patativa, muito comum na Região do Cariri e do Assaré como sua marca distintiva, deixou como legado mais de dez livros publicados, títulos honoríficos, dentre os quais, Doutor Honoris Causa, Cidadão Cearense, troféu Sereia de Ouro, medalhas, prêmios e o reconhecimento como o maior poeta popular do Nordeste e, porque não dizer, do país. A obra do Patativa é referência para todo aquele que pretende estudar a cultura popular cearense.

Sua temática preferida é o contraste da vida sertaneja, numa luta de protesto contra a injustiça social. Cante lá, que eu canto cá é uma poesia que resume essa visão do mundo sertanejo dividido, onde se confrontam movimentos de tese e antítese, expressos pela contradição entre a vida na cidade e no campo. Seus versos revelam a beleza do sertão que lhe deu, "de mão beijada", um mundo cheio de rimas.

Apresentando o seu lado criativo, o poeta enriqueceu o léxico brasileiro com diversos vocábulos e expressões populares. Só para se ter uma ideia, serão citados alguns exemplos:

- Bode melado - Homem muito feio, de cabelo tendente a louro. E aquele lôro, / bode melado / tá inganado/ comigo agora. (PA).

- Bolo de fim de fêra - Algo sem valor; insignificante. Taram pensando que voto/ é bolo de fim de fêra?(PA).

- Bote bem curto - Fiscalizar; regularizar um assunto; imprensar alguém; expressão semelhante a manter as rédeas curtas. Mamãe, a senhora bote /bem curto naquele loro. (PA). 
- Boto pedra no sapato - Dificultar a vida, a campanha, os negócios. Mas agora eu boto / pedra no sapato / destes candidato. (PA).

- Tê comprado cartia pro o ôtro lê - Ser enganado, traído, ludibriado. Só pruquê meu casamento/Foi triste e foi azalado/Foi mesmo que eu tê comprado/Cartia pro ôtro lê. (PA).

- Que me deu de mão beijada - De graça, gratuitamente, espontaneamente. Dar sem remuneração, sem nada receber em troca. Sertão, minha terra amada, / De bom e sadio crima,/ Que me deu de mão beijada,/ Um mundo cheio de rima. (PA). (NAS, 1986, p. 177; CAB, 1982, p. 499).

- Perde a cilôra - Perder tudo; ficar sem nada, na miséria. Ele na outra inleição/ quaje que perde a cilôra. (PA).

- Vara de ispichá coro - [vara-de-apagar-vela, pau de virar tripa]. Sujeito alto e magro; espanador de lua. Tão magro que é parecido/ Com vara de ispichá coro. Vara de bater feijão. (PA). Pessoa muito alta e magra. (NAS, 1986, p. 310). Vara (ou pau) de virar tripa. Pessoa alta e magra. (CAB, 1982, p. 732).

- Corri a vista - Examinar ligeiramente, de relance. (CAB, 1982, p. 252). Corri a vista na sala,/ E entrei por aqui assim:/ - Viva a noiva e viva o noivo. (PA).

- Correu estreito - Viver situação de aperturas, de dificuldades. (CAB, 1982, p. 253). Só canta o sertão dereito/ Com tudo quanto ele tem,/ Quem sempre correu estreito,/ Sem proteção de ninguém. (PA).

- Coberto de sete capa - Escondido. Amufambado. Coisa ou assunto guardado com muito segredo. Em absoluto segredo. Debaixo de sete chaves - (CAB, 1982, p. 213). Coberto de sete capas (Ceará). Em grande sigilo, muito ocultamente. Tetê foi farsa comigo/ Dibaxo de sete capa. (PA). (NAS, 1986, p. 53).

- Dobre a língua - Ter comedimento nas palavras; falar com mais respeito. (NAS, 1986, p. 166). E me gritou: atrivido,/Seu sem vergonha inchirido/Dobre a língua má criado. (PA). Expressão empregada apenas no tempo imperativo, quando se repele insultos ou se exige mais comedimento no falar. (CAB, 1982, p. 307).

- Fazer mão de gato - Roubar; furtar. (CAB, 1982, p. 383). E pra fazer mão de gato/ em favor do candidato,/ já fui cabo eleitoral. (PA).

- Puxando fogo - (Ceará) Ficar meio ébrio; quente; empilecado; embriagado. Parece um cabra valente/ Quando tá puxando fogo. (PA). Ficar em questão de meia embriaguez por efeito de bebidas alcoólicas. (NAS, 1986, p. 130). 
- Sem pé nem cabeça - Coisa ilógica, sem nexo. (CAB, 1982, p. 145). Senão com pôco esta históral Fica sem pé e sem cabeça. Sem pés nem cabeça. (PA). Despropositado, disparatado, desarrazoado. (NAS, 1986, p. 228).

- Não vale um xis - Nada valer; ser sem préstimo; não possuir caráter nem dignidade. (CAB, 1982, p. 765). Muita coisa se padece,/ Só porque ninguém conhece/ No mundo véio, infeliz,/ Onde é que a bondade mora; Às vez, o que é bom por fora/ Por dentro não vale um xis. (PA). Não vale um X. Não presta para nada. Antiga moeda de cobre em que figura um $\mathrm{X}$ indicativo do valor de 10 réis, a menor das divisionárias. (GIR, 2000, p. 360).

E, complementando nosso estudo, seguem-se alguns exemplo de PAR̂̂MIAS:

- Mais, porém quem nasceu pra derréis não chega a vintém. A expressão compara duas moedas da época, onde o valor de uma é inferior ao da outra. (OP, 1999, p. 31). (N.E.).

- Cada macaco em seu galho! (OP, 1999, p. 78). (PA).

- Quem precisa é quem se estira. (PA).

- Mas aquilo sabe onde carnero maia e andorinha dorme. (OP, 1999, p. 64).

- Aquele moço nom é de teoregas nem de intifas. (OP, 1999, p. 76).

- Largue o cabresto, que a besta é alheia. (OP, 1999, p. 42).

- Mais a mim tu non mingana, não, qui não cumi pato in tempo de piqueno. (OP, 1999, p. 64).

- ... non meto a mão na seara alheia. (OP, 1999, p. 77).

- Quem ama o feio, bonito the parece. (OP, 1999, p. 94).

- Eu cá não boto água a pinto. (OP, 1999, p. 82).

- A cobardia é filha da falta de convicção. (OP, 1999, p. 97).

- Quem não tem pente ouro,/ Usa cacho de fulô... (OP, 1999, p. 109).

- Pernas pra que te quero! (OP, 1999, p. 119).

- O boi sabe que cerca fura. (OP, 1999, p. 142).

- _ _ Por certo, respondeu a Guida, quem não deve não teme! (OP, 1999, p. 148).

- O que os olhos não vêem coração não sente. (OP, 1999, p. 163).

- É simples__redarguia o juiz. O crime nivela, como a virtude. (OP, 1999, p. 166). 


\section{CONSIDERAÇÕES FINAIS}

A análise dos exemplos apresentados revela a importância, sempre crescente, de que se revestem os estudos sobre as unidades fraseológicas para uma comunicação mais eficaz. O que vale é não considerar as palavras isoladas, mas a estrutura fraseológica como um todo.

Esses conjuntos de palavras, cujos elementos se ligam para exprimirem determinadas ideias comuns, acrescentam muitas vantagens às necessidades de expressão. Primeiro, por se apresentarem em grupos, poupando esforço e trabalho e, depois, por passarem de geração a geração, através da língua, as marcas sociais e culturais do povo cearense, tais como, a expressividade e a criatividade no processo comunicativo.

Diante do exposto, destaca-se o relevante papel sociocultural das unidades fraseológicas, reflexos do passado e, ao mesmo tempo, geradoras de novas formas de expressão linguística e sugere-se que, nas práticas de sala de aula, o estudo dos provérbios seja contemplado durante as aulas de Língua Portuguesa, explorando sua forma, suas características e as possíveis situações de uso, tanto nos discursos formais, quanto nos informais.

\section{REFERÊNCIAS}

ALENCAR, Maria Silvana Militão de. Entrevista com Patativa. In: A linguagem regional popular na obra de Patativa do Assaré: aspectos fonético-lexicais. Dissertação (Mestrado em Linguística) - Universidade Federal do Ceará, Fortaleza, 1997.

ALENCAR, Adriana Nuvens de, BATISTA, Maria de Fátima B. de M. Carta a um jovem poeta ("Popular"): leitura semiótica de um manuscrito epistolar de Patativa do Assaré in Acta Semiotica et Lingvistica, Vol 22, Ano 41, N². Portal de Periódicos da UFPB, 2017, ASSARÉ, Patativa do. Aqui tem coisa. 2. ed. Fortaleza: Secult, 1994.

Cante lá que eu canto cá. 8. ed. Petrópolis: Vozes, 1992.

BARBOSA, Maria Aparecida. Questões relevantes na descrição fraseológica. Cadernos do CNLF, v. X, n. 14, 23 ago. 2006.

BIDERMAN, Maria Tereza. Dicionário contemporâneo de português. Petrópolis: Vozes, 1992.

CABRAL, Tomé. Novo dicionário de termos e expressões populares. Fortaleza: UFC, 1982. CORPAS PASTOR, Glória. Manual de fraseologia española. Madrid: Editorial Gredos, 1996. GIRÃO, Raimundo. Vocabulário popular cearense. Fortaleza: Edições Demócrito Rocha, 2000. LAPA, Manuel Rodrigues. Estilística da língua portuguesa. 4. ed. São Paulo: Martins Fontes, 1998.(Ensino Superior). 
MARTINET, André. A lingüística sincrônica: estudos e pesquisas. Trad. Lílian Arantes. Rio de Janeiro: Tempo Brasileiro, 1974.

NASCENTES, Antenor. Tesouro da fraseologia brasileira. 3. ed. Por Olavo Aníbal Nascentes. Rio de Janeiro: Nova Fronteira, 1986. (obras de Referência).

ORTIZ ALVAREZ, M. L. Expressões Idiomáticas do português do Brasil e do espanhol de Cuba: Estudo contrastivo e implicações para o ensino de português como língua estrangeira. Tese de Doutorado em Linguística Aplicada - Instituto de Estudos da Linguagem, Universidade de Campinas, Campinas: 2000.

. O papel das metáforas nas Expressões Idiomáticas. Revista Horizontes de Linguística Aplicada, Brasília, v. 4, n. 1, p. 19-36, 2004.

PAIVA, Manoel de Oliveira. Dona Guidinha do Poço. 3. ed. São Paulo: Ática, 1999.

PEREIRA, Lúcia Miguel. Apresentação. Rio de Janeiro: Tecnoprint Gráfica, 1965.

SILVA NETO, Serafim da. Introdução ao estudo da língua portuguesa no Brasil. 2. ed. Rio de Janeiro: Instituto Nacional, 1963.

VILELA, Mário Augusto do Quinteiro. Metáforas do nosso tempo. Coimbra: Almedina, 2002. 